\title{
Continuous quality improvement in infectious diseases
}

$\mathrm{T}$ HE MEASUREMENT AND CONTINUOUS IMPROVEMENT OF the quality of medical care which we deliver has become an important concept in today's health care environment. The concept of continuous quality improvement (CQI) is a general model for providing quality in any type of organized activity that grew out of a statistical concept developed in the 1930s by Dr WA Shewhart (1). This concept suggested that the limits of random variation in a product or a task could be recorded and monitored with limits of control established such that workers would be responsible for making any necessary adjustments to the processes involved for the product or task if any significant deviation occurred. This concept was refined further by Deming (2) and Juran (3), and was taught as a philosophy to Japanese industry in the late 1940s and early 1950s. The quality of many Japanese products and the cost of producing them has since become legendary. Most industries are now implementing the concepts of CQI with the exception of the health care industry, and hence, the concept remains unknown to a large number of health care workers (4).

Although there is no unanimity on how to define 'quality', a widely accepted definition is: "a continuous effort by all members of an organization to meet the needs and expectations of the customer" $(5,6)$. Exploring this definition further allows one to realize the ramifications of this definition. The continuous effort emphasizes the value of striving to exceed the existing standards rather than merely attaining them, which is a departure from the traditional approach to quality assurance. References to expectations recognize that the experiences of patients and their assessments of results represent valid indicators of quality. The refer- 
ence to 'customer' in the context of health care is taken in its widest context and may represent an individual or an organization. Taken in this context we acknowledge the existence of not only the patient, but also nursing staff, physicians, support staff and others within the hospital organizational structure. For example, physicians may be seen as customers of the pharmacy and the laboratory in one sense because the physicians rely on laboratory results to perform their own work; in another sense, the laboratory and pharmacy are customers of the physician - they only begin their work after processing physician orders.

In simple terms CQI creates the need for departments and organizations within the hospital or clinical setting to identify their customers, their expectations and the tasks in any activity directed towards the customer (4).

A necessary prerequisite of CQI is that management must be absolutely and relentlessly committed to the improvement of quality. It should also be emphasized that CQI is not a short term process but a long term horizontal process that involves all levels of an organization from the top to the bottom. The achievement of quality thus depends more on an organized system design, adequate training, long term direction and strong leadership, rather than an individual motivation.

CQI also recognizes and analyzes variation in medical care, including differences in diseases, differences in presentations of the same disease, patient response to disease, patient expectations, staff mix and availability of diagnostic tests. Reporting, charting and other methods are used to identify predictable patterns and variations, and to provide a framework in which to formulate efforts to improve quality. These efforts include modifying processes to reduce redundancy, wastage and expense.

Several specific examples of the adoption of this philosophy in infectious diseases are available. An antimicrobial use committee working towards the optimal use of antimicrobials in the most cost-efficient manner in an institution represents a process in which many levels of the organization are involved (or should be involved) to improve the quality of care delivered to the patients and, at the same time, satisfying the prescribing physicians. The laboratory management committees for diagnostic clinical microbiology laboratories with representatives from within the laboratory administration and 'consumers' of the laboratory information also provides an ideal opportunity for improving the delivery of results. In infection control, rather then focusing on rates and distributions of nosocomial infections, efforts are directed towards determining the common denominator of specific infection rates. The generation of practice guidelines for the management of sexually transmitted diseases, immunization guidelines and treatment guidelines for specific infectious diseases also represent efforts to improve the process of care. CQI will involve the infectious diseases physician in many more aspects of clinical care, particularly in a subspecialty which crosses so many traditional disciplinary boundaries. As the decade of an increasingly fiscal outlook on health care evolves, the infectious diseases physician is ideally suited to take a leading role in CQI.

\section{REFERENCES}

1. Shewhart WA. The application of statistics as an aid in maintaining quality of a manufactured product. J Am Stat Assoc 1925;20:546-8.

2. Demin WE. Out of the Crisis. Cambridge: Massachusetts Institute of Technology, Center for Advance Engineering Study, 1986.

3. Juran JM. Planning for Quality. New York: The Free Press, 1988.

4. Berwick DM. Continuous improvement as an ideal in healthcare. N Engl J Med 1989;320:53-6.

5. Laffel G, Blumenthal D. The case for using industrial quality management science in healthcare organizations. JAMA 1989;262:2869-73.

6. Health Services Research Groups. Quality of care: What's quality and how can it be measured? Can Med Assoc J 1992;146:2153-8. 


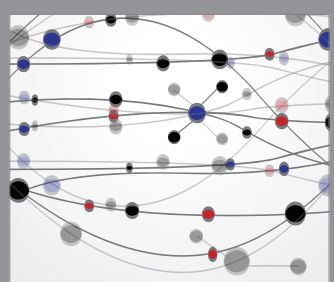

The Scientific World Journal
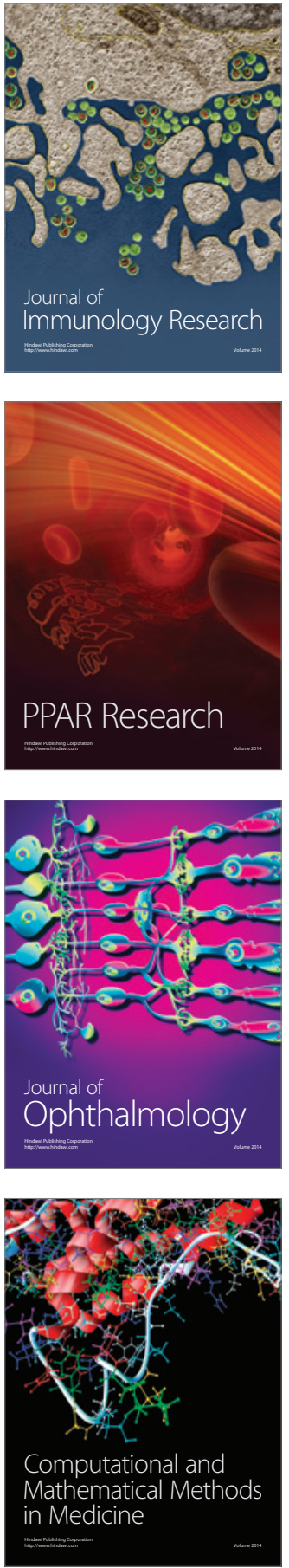

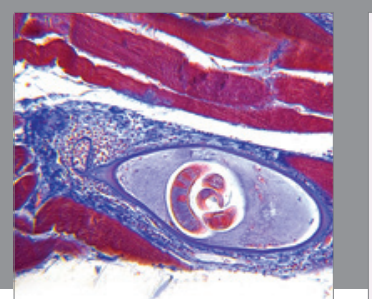

Gastroenterology Research and Practice

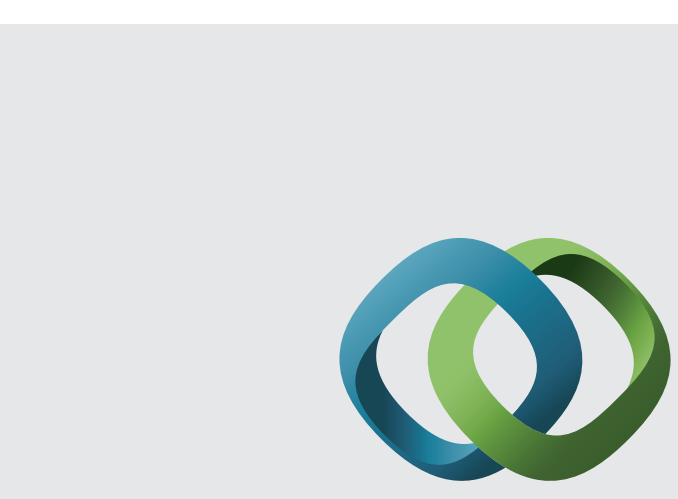

\section{Hindawi}

Submit your manuscripts at

http://www.hindawi.com
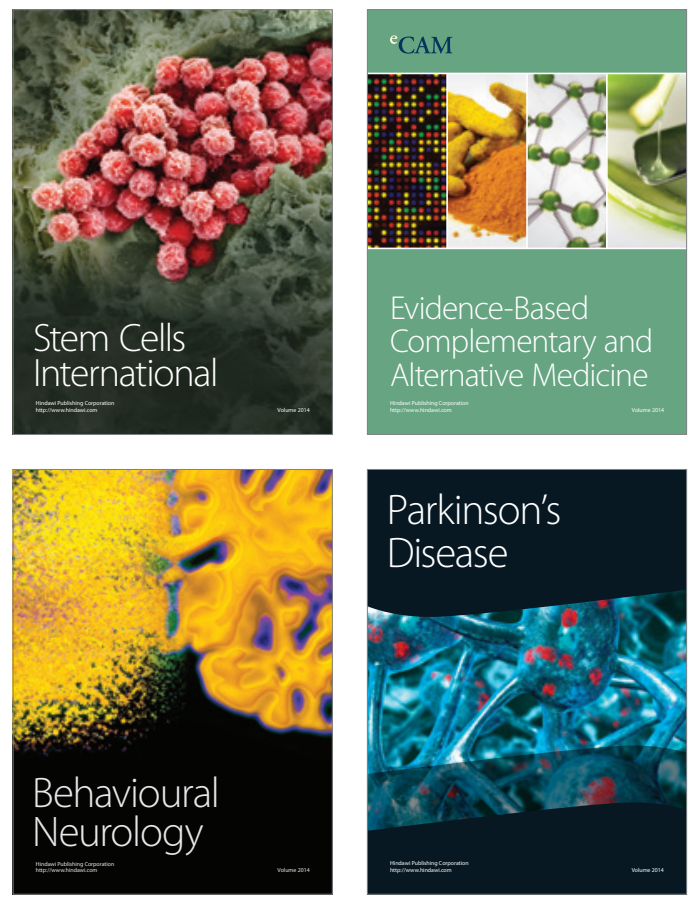
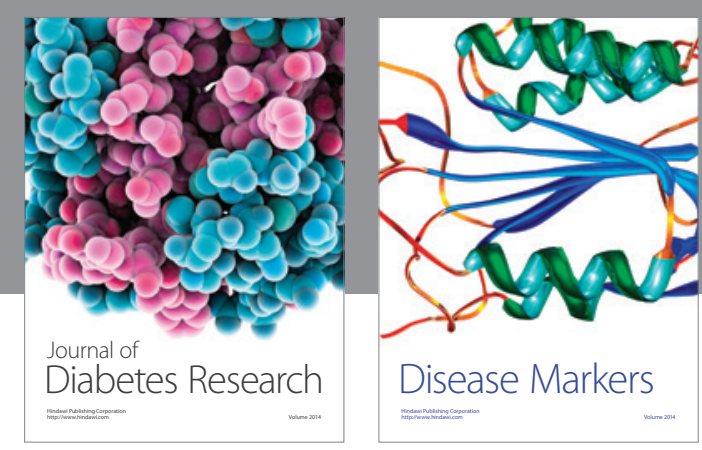

Disease Markers
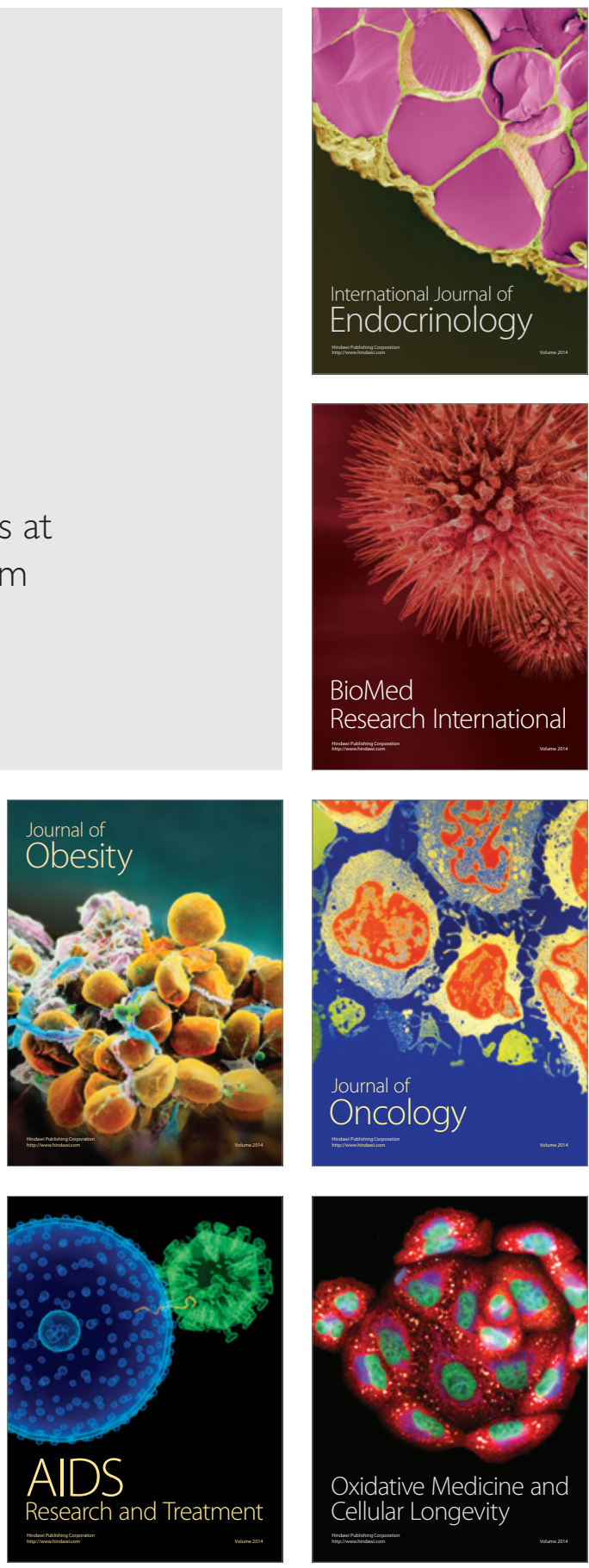